\title{
First aphidiine wasp from the Sakhalinian amber
}

\author{
Elena M. Davidian, Maryna O. Kaliuzhna, and Evgeny E. Perkovsky \\ Acta Palaeontologica Polonica 66 (3), 2021: s059-s065 doi:https://doi.org/10.4202/app.00843.2020
}

The first ichneumonoid aphidiine wasp species from Sakhalinian amber (middle Eocene) is described. Ephedrus rasnitsyni Davidian and Kaliuzhna sp. nov. is the oldest named aphidiine female, the first fossil aphidiine from Asia, and the oldest named species of the Ephedrus. Ephedrus rasnitsyni Davidian and Kaliuzhna sp. nov. and the two fossil species of Ephedrus, i.e., Ephedrus primordialis from Baltic amber (late Eocene) and Ephedrus mirabilis from Camoins-les-Bains (early Oligocene), presumably belong to the Ephedrus plagiator species group of the subgenus Ephedrus sensu stricto, and new species differs from them in having a longer petiole and a rather long $3 \mathrm{M}$ vein that does not reach the forewing margin. It additionally differs from E. primordialis by having longer ovipositor sheaths. The new species is most similar to the extant Ephedrus validus and Ephedrus carinatus, from which it differs by the less elongated F1, absence of notauli, and by ovipositor sheaths that are 3.0 times as long as wide.

Key words: Hymenoptera, Ichneumonoidea, Braconidae, Aphidiinae, Eocene, Oligocene, Baltic amber, Sakhalinian amber.

Elena M. Davidian [GDavidian@yandex.ru; ORCID:

https://orcid.org/0000-0003-3804-4618], All-Russian Institute of Plant Protection (FSBSI VIZR), Podbelskogo, 3, St. Petersburg - Pushkin, 196608 Russian Federation. Maryna O. Kaliuzhna [kaliuzhna.maryna@gmail.com; ORCID: https://orcid.org/0000-0002-9265-0195], I.I. Schmalhausen Institute of Zoology of NAS of Ukraine, B. Khmelnytskogo Str. 15, 01030 Kyiv, Ukraine.

Evgeny E. Perkovsky [perkovsk@gmail.com; ORCID: https://orcid.org/0000-0002-7959-4379], I.I. Schmalhausen Institute of Zoology of NAS of Ukraine, B. Khmelnytskogo Str. 15, 01030 Kyiv, Ukraine; A.A. Borissiak Paleontological Institute of the Russian Academy of Sciences, Profsoyuznaya Str. 123, 117997 Moscow, Russian Federation. 
distribution, and reproduction in any medium, provided the original author and source are credited.

Fof 